\title{
Free-breathing respiratory self-gated Golden angle RAdial Three-dimensional whole-heart isotropic cine imaging for left ventricular volumetric Evaluation (GRATE) - comparison with conventional 2D breath-hold cine imaging
}

\author{
Karen Holst, Martin Ugander, Andreas Sigfridsson \\ From 19th Annual SCMR Scientific Sessions \\ Los Angeles, CA, USA. 27-30 January 2016
}

\section{Background}

Breath holding during imaging can be challenging for patients with heart disease and can affect image quality as well as alignment of images acquired during different breath holds. The purpose of this study was to develop a free breathing respiratory self-gated cardiac magnetic resonance (CMR) technique for left ventricular (LV) volume measurements.

\section{Methods:}

Acquisition. A balanced steady-state free precession (bSSFP) sequence using a 3-dimensional (3D) golden angle radial acquisition order was implemented for acquisition of an image volume covering the whole heart (GRATE). The sequence was used to image 8 healthy volunteers during free breathing and over several cardiac and respiratory cycles. A stack of short-axis (SA) slices, as well as 4-, 3- and 2-chamber views, were acquired with a conventional Cartesian 2-dimensional (2D) breath held cine bSSFP for comparison. Both methods were applied twice on each subject with a break outside the scanner in between. GRATE parameters were: FOV $352 \mathrm{~mm}$, isotropic voxels $2 \times 2 \times 2 \mathrm{~mm}$, TR/TE $2.7 / 1.3 \mathrm{~ms}$, flip angle $65^{\circ}$, 900,000 radial spokes.

Respiratory Self-gating. Respiratory self-gating (SG) signals from the data were extracted retrospectively from the $k$-space center point in each radial spoke using a twosided low-pass filter adapted to each dataset. Trigger

Department of Clinical Physiology, Karolinska Institutet and Karolinska University Hospital, Stockholm, Sweden

\section{Results}

The number of radial spokes in each unique cardiac and respiratory phase combination over all subjects was 25,165 \pm 137 . There was no difference between GRATE and 2D with regards to LV ejection fraction (EF) (60 $\pm 4 \%$ vs. 61 $\pm 4 \%, \mathrm{p}=0.38)$ or stroke volume (SV) $(109 \pm 21 \mathrm{ml}$ vs. $116 \pm 24 \mathrm{ml}, \mathrm{p}=0.08)$. The test re-test difference did not differ between GRATE and 2D for either EF ( $2 \pm 2 \%$ vs. 1 $\pm 4 \%, \mathrm{p}=0.55)$ or SV $(1 \pm 10 \mathrm{ml}$ vs. $1 \pm 9 \mathrm{ml}, \mathrm{p}=0.64)$. The difference between GRATE and 2D measurements was $1 \pm 4 \%$ for EF, and $7 \pm 10 \mathrm{ml}$ for SV.

\section{Conclusions}

GRATE and conventional 2D cine showed similar absolute values and test re-test repeatability for LVEF and SV in healthy volunteers. 3D golden angle radial acquisition 


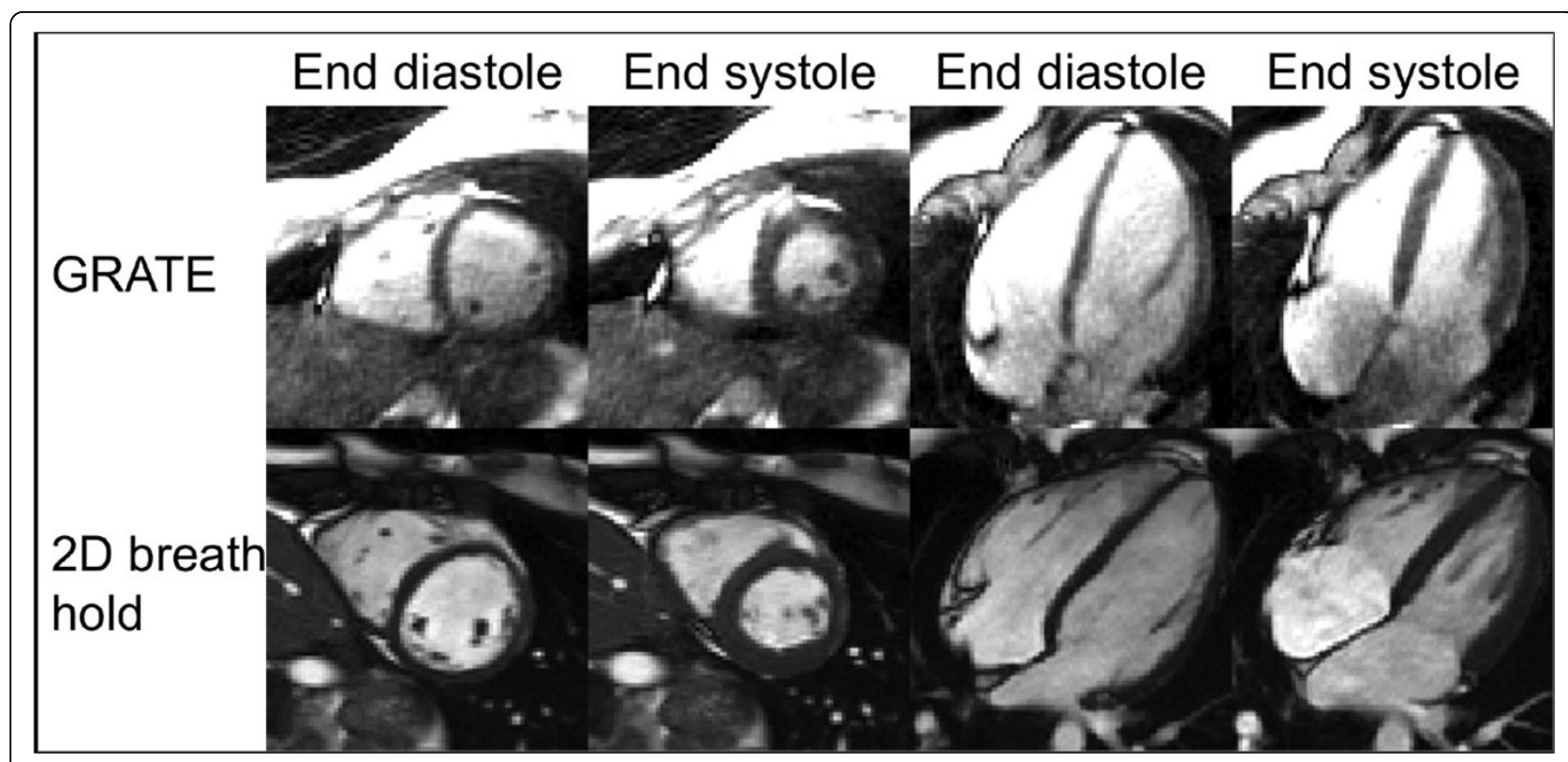

Figure 1

during free breathing enabled retrospective sorting of the data from respiratory self-gated signals and ECG, and could correctly measure LV volumes. Furthermore, GRATE imaging allows for unrestricted multiplanar reformatting after acquisition.

Published: 27 January 2016

doi:10.1186/1532-429X-18-S1-P242

Cite this article as: Holst et al:: Free-breathing respiratory self-gated

Golden angle RAdial Three-dimensional whole-heart isotropic cine imaging for left ventricular volumetric Evaluation (GRATE) - comparison with conventional 2D breath-hold cine imaging. Journal of Cardiovascular Magnetic Resonance 2016 18(Suppl 1):P242.
Submit your next manuscript to BioMed Central and take full advantage of:

- Convenient online submission

- Thorough peer review

- No space constraints or color figure charges

- Immediate publication on acceptance

- Inclusion in PubMed, CAS, Scopus and Google Scholar

- Research which is freely available for redistribution 